\title{
INTRODUCCIÓN AL MONOGRÁFICO
}

Lectura y sociedad es el título genérico del nuevo número de la revista RESED correspondiente al año 2016. La selección del tema ha venido dada por dos razones fundamentales, por un lado la orientación profesional de las dos coordinadoras de este número ya que ambas desarrollan su labor universitaria en el área de Didáctica de la Lengua y la Literatura y, por tanto, era natural que eligiéramos el tema de la lectura como eje central de todas las aportaciones. Por otro lado, el peso que socialmente se le da a la lectura ha sido otra de las razones para optar por este tema.

Las reflexiones sobre la lectura y su valor social pueden hacerse desde muy distintas ópticas (sociológicas, filológicas, didácticas...) y por diferentes agentes (investigadores, docentes, autores, libreros, bibliotecarios...). El presente número ha intentado dar voz a unas y otros y el resultado es el número que tienen entre manos.

El monográfico se abre con el texto del profesor Juan Mata "Leer con otros. Aportaciones a la dimensión social de la lectura" en el que se analiza con solidez el importante papel social de la lectura y cómo el modo en que en ocasiones se aborda en el ámbito escolar — donde el texto se sitúa como objeto último de estudio, dejando al lado las vivencias personales - puede generar desafección hacia la literatura. Frente a esto se analizan las ventajas que suponen para el establecimiento de relaciones positivas con el libro las prácticas de lectura colectiva como las tertulias literarias dialógicas incluso en aquellos contextos traumáticos, donde sirve para paliar situaciones de miedo, marginación o exclusión.

El estudio firmado por el profesor Pedro Cerrillo y Aantxa Sanz "Lectura, Iglesia y sociedad" conecta con el trabajo previo al desarrollar cómo a lo largo de la historia y, específicamente, en aquellos momentos en los que Gobierno e Iglesia caminan de la mano la lectura se convierte en algo dirigido y encaminado a la difusión y consolidación de una determinada ideología. Tras un recorrido histórico se pone el foco de atención en lo sucedido en España durante la etapa franquista y, en concreto, al papel jugado por el Gabinete de Santa Teresa en la selección de obras destinadas a niños de hasta 15 años; algo hoy día aparentemente superado pese a los intentos por prohibir determinadas obras, como ha sucedido en algunos países y entre algunos lectores con Tres con Tango.

Por su parte, José Rovira en "Del blog de LIJ 2.0 al booktuber en la promoción del hábito lector" analiza el papel que juegan las nuevas tecnologías en prácticas que guardan una estrecha relación con la lectura social, pues permiten compartir experiencias y también promocionar determinadas obras. Con todo ello se han ido perfilando en nuestros días nuevas formas de acceso a la lectura que no se pueden obviar y que deben ser consideradas a la hora de valorar los hábitos lectores y fomentar la lectura literaria. 
Rosa Tabernero centra su trabajo "Lecturas adultas y lecturas infantiles. El universo de Kitty Crowther en la formación del mediador como lector literario" en la redefinición del concepto de lector infantil que atienda a las diferencias con las que se enfrenta un niño y un adulto a un mismo texto literario; de manera concreta se analizan las obras de Kitty Crowther atendiendo a aspectos diversos como la relación imagen-texto y a los temas: miedo, soledad, muerte, incomunicación, competitividad, sexismo, diversidad, etcétera, considerados difíciles para un receptor infantil pero que pueden llegar adecuadamente al mismo a través de una adecuada mediación.

Continuando con la importancia de la mediación y la formación de los futuros docentes habría que situar el estudio de Ester Trigo "El papel de la formación inicial y permanente en el profesorado para forjar lectores" donde se realiza un pormenorizado recorrido por las actividades ofertadas por el Centro del Profesorado de Cádiz y la Consejería de Innovación de la Junta de Andalucía para mejorar la capacitación de los estudiantes egresados de los Grados de Magisterio de la Universidad de Cádiz, sin desatender a los propios contenidos de las asignaturas relacionadas con la formación literaria de los mismos y sin olvidar la oferta de diferentes másteres y de la escuela de doctorado de la citada universidad. El recorrido que se hace por las diferentes actividades resulta sin duda de notable interés para aquellos profesores interesados en mejorar su labor y permite el establecimiento de vínculos claros entre la formación inicial y la aún más necesaria formación permanente, tal y como recoge el título.

El trabajo de Beatriz Sánchez y Lourdes Sánchez guarda a su vez relación con el texto previo, ya que en él se atiende de manera concreta a la selección de obras que los alumnos del Grado en Educación Infantil realizaron tras cursar la asignatura de Literatura Infantil y Fomento de la Lectura. A partir del listado de títulos generado desde las elecciones de los alumnos se ha procedido a valorar la presencia de los diferentes géneros, donde se aprecia que la narrativa ocupa el lugar más destacado, coincidiendo con la propia producción editorial, aunque se incluyen algunas obras poéticas y algún texto teatral; en el análisis de los motivos de la selección parece que son criterios utilitaristas derivados del vínculo que trata de establecerse con las posibilidades de trabajo de determinados aspectos curriculares con los textos lo que prima, sin destacarse apenas el uso de los mismos como fuente de disfrute, algo que parecen dar como implícito en las propias características de la edición de las obras, donde se observa un dominio claro del álbum ilustrado, y que solo se destaca en casos concretos, especialmente en lo que a la poesía se refiere.

En el caso del trabajo de Paula Rivera son las posibilidades para trabajar la interculturalidad a través de la literatura juvenil lo que se aborda partiendo de la obra Algún día, cuando pueda llevarte a Varsovia de Lorenzo Silva; para ello se elabora una propuesta didáctica en consonancia con el recorrido teórico que abre el trabajo. Una línea similar, pero centrada en una experiencia concreta "La lectura de los Aerolitos de Carlos Edmundo de Ory en contextos interculturales: una experiencia en una escuela 
polaca" escrito por Milagrosa Parrado y Agnieszka Wilczyńska evidencia cómo la lectura de los clásicos literarios permite crear nexos entre estudiantes de diferentes ámbitos culturales y geográficos por existir espacios temáticos concretos para el encuentro.

Cierra este bloque la aportación de Salvatore Patera "La cultura como proyecto educativo de una narración compleja" en la que a través de un amplio recorrido bibliográfico se reflexiona sobre la importancia de la intersubjetividad como espacio para el diálogo y se destaca el papel de la literatura y de la narración, en concreto, como elemento clave a la hora de leer e interpretar la propia cultura.

A continuación se recogen varios trabajos que incluyen reflexiones y experiencias concretas desarrolladas por las instituciones o en espacios concretos para fomentar la lectura. En primer lugar se hallan las reflexiones de dos escritores de notable repercusión en el panorama de la literatura infantil y juvenil como son Eliacer Cansino y Carmen Gil. En el primer caso son varias notas sobre la lectura lo que se ofrece donde vivencias personales con el mundo del libro marcan toda una serie de sugerentes párrafos; por su parte, Carmen Gil a través de varias preguntas realiza un recorrido por la situación de la producción literaria infantil en la actualidad y por la propia situación del escritor a través de su experiencia personal.

Siguen luego varios trabajos en los que se recogen diferentes experiencias con la lectura desde distintas perspectivas. Así, Ricardo Chamorro traza con exactitud los diferentes objetivos del Plan Universitario en Fomento del Libro, la Lectura y la Escritura integrado en la planificación de la biblioteca de la Universidad de Cádiz y donde también colabora el Servicio de Publicaciones de la citada institución. Por su parte, Julia Sánchez recorre el papel del librero en el fomento lector con datos de estudios, pero desde su propio conocimiento como propietaria de una librería especializada en literatura infantil y juvenil. Cierra la sección el texto de José Antonio Lucero que recoge los aspectos fundamentales de una experiencia en el aula en la que las nuevas tecnologías juegan un papel central en el acceso a la obra literaria.

De igual modo, en el volumen se incluyen las reseñas de dos obras recientes, realizadas por Inmaculada Barra y Candela Jiménez; en el primero de los casos se trata además de un libro claramente conectado con el tema de este monográfico, ya que realiza un recorrido crítico por el trabajo Nuevas líneas de investigación e innovación en la educación literaria coordinado por los profesores Rafael Jiménez Fernández y Manuel Francisco Romero Oliva. También se recogen aquí un recorrido por los contenidos abordados en el III Congreso Internacional Virtual de Educación Literaria realizado por Carmen María Sánchez.

Desde estas diferentes aportaciones se ha tratado de ofrecer una imagen rica y variada de los múltiples elementos que se ven implicados en el acceso a la lectura, la creación de hábitos lectores y la educación literaria; se atiende así al papel jugado por los 
mediadores bibliotecarios, libreros y adultos más capacitados en general, entre los que el profesorado posee un peso más que destacado; en relación con este último aspecto se aportan datos sobre las posibilidades de formación permanente existentes para el mismo, sobre prácticas en el aula y propuestas para introducir determinadas cuestiones, al tiempo que se resalta la importancia específica que para la lectura y el fomento lector tienen las nuevas tecnologías en nuestros días donde la red se ha convertido en un espacio privilegiado para compartir experiencias y acaso para atraer a sujetos que de otra forma no se interesarían por la literatura.

Lourdes Sánchez Vera y Beatriz Sánchez Hita, coordinadoras del número. 